\title{
Racionalidades em disputa: formação docente na esfera dos planos municipais de educação no Rio Grande do Sul
}

\author{
Rosimar Serena Siqueira Esquinsani ${ }^{1}$ \\ Valdocir Antonio Esquinsani ${ }^{2}$
}

\section{RESUMO}

O texto discute concepções de formação docente expressas em Planos Municipais de Educação, a partir dos registros da lei, considerando a existência de dois modelos de racionalidade: a racionalidade técnica e a racionalidade prática ou crítica. A pesquisa foi conduzida por uma metodologia analítico-reconstrutiva, através do procedimento da análise de conteúdo, materializado a partir de uma base documental que considerou as leis dos PMEs dos 30 maiores municípios sul-rio-grandenses. Conclui que as estratégias apresentadas, nos documentos examinados, quando imediatas e factíveis, são vinculadas à racionalidade técnica, todavia as estratégias com prazo indefinido, são da seara da racionalidade crítica. Assim, a disputa entre as duas concepções de racionalidade não se dá no registro legal, mas no campo da possibilidade de efetivação real de uma estratégia ou ação de formação docente.

Palavras-chave: Formação docente. Plano municipal de educação. Administração de redes e sistemas de ensino.

\section{Rationalities in dispute: teacher training in the sphere of municipal education plans in Rio Grande do Sul state}

\begin{abstract}
The text discusses conceptions of teacher formation expressed in Municipal Plans of Education, from the records of the law, considering the existence of two models of rationality: technical rationality and practical or critical rationality. The research was conducted by an analytical-reconstructive methodology, through the content analysis procedure, materialized from a documentary base that considered the laws of the PMEs of the 30 largest municipalities of Rio Grande do Sul state. It concludes that the presented strategies, in the documents examined, when immediate and feasible, are linked to the technical rationality, however the strategies with indefinite term, are of the area of critical rationality. Thus, the dispute between the two conceptions of rationality does not take place in the legal register, but in the field of the possibility of actual implementation of a strategy or action of teacher training.
\end{abstract}

Keywords: Teacher training. Municipal education plan. Administration of networks and education systems.

\footnotetext{
${ }^{1}$ Doutora em Educação. Professora e pesquisadora do Programa de Pós-graduação da Universidade de Passo Fundo - UPF.

${ }^{2}$ Professor e pesquisador na Universidade de Passo Fundo - UPF.
} 


\title{
Racionalidades en disputa: formación docente en la esfera de los planes Municipales de Educación en Rio Grande do Sul
}

\begin{abstract}
RESUMEN
El texto discute concepciones de formación docente expresadas en Planes Municipales de Educación, a partir de los registros de la ley, considerando la existencia de dos modelos de racionalidad: la racionalidad técnica y la racionalidad práctica o crítica. La investigación fue conducida por una metodología analítico-reconstructiva, a través del procedimiento del análisis de contenido, materializado a partir de una base documental que consideró las leyes de los PMEs de los 30 mayores municipios sur-rio-grandenses. Concluye que las estrategias presentadas, en los documentos examinados, cuando son inmediatas y factibles, están vinculadas a la racionalidad técnica, sin embargo las estrategias con plazo indefinido, son de la mina de la racionalidad crítica. Así, la disputa entre las dos concepciones de racionalidad no se da en el registro legal, sino en el campo de la posibilidad de efectividad real de una estrategia o acción de formación docente.
\end{abstract}

Palabras-clave: Formación docente. Plan municipal de educación. Administración de redes y sistemas de enseñanza.

\section{Racionalidades em disputa: formação docente na esfera dos Planos Municipais de Educação no Rio Grande do Sul}

O texto objetiva discutir as concepções de formação docente expressas em Planos Municipais de Educação (Art. 8 . da Lei 13.005/2014, BRASIL, 2014), a partir das racionalidades manifestas nos registros contidos na lei, considerando dois modelos de racionalidade: o modelo da racionalidade técnica e o modelo da racionalidade prática ou racionalidade crítica.

Para cumprir seu objetivo, a pesquisa que deu origem ao texto em tela foi realizada, prioritariamente, em base documental e, subsidiariamente, em revisão bibliográfica temática, conduzida por uma metodologia analítico-reconstrutiva e pautada pelo procedimento da análise de conteúdo, materializado através da descrição, categorização, exame e reconstrução de argumentos, apresentando potenciais subsídios ao debate sobre racionalidades implicadas na formação docente.

A pesquisa, em base documental, considerou os Planos Municipais de Educação dos trinta (30) maiores municípios do Rio Grande do Sul em termos populacionais. Desta feita, o corpus documental foi composto pelas legislações que aprovam os PMEs, coletadas junto ao site: http://pne.mec.gov.br/planos-de-educacao/situacao-dos-planos-de-educacao. Por ordem 
de população, os trinta municípios sul-rio-grandeneses que tiveram suas legislações examinadas foram: Porto Alegre; Caxias do Sul; Pelotas; Canoas; Santa Maria; Gravataí; Viamão; Novo Hamburgo; São Leopoldo; Rio Grande; Alvorada; Passo Fundo; Sapucaia do Sul; Uruguaiana; Cachoerinha; Santa Cruz do Sul; Bagé; Bento Gonçalves; Erechim; Guaíba; Cachoeira do Sul; Esteio; Ijuí; Santana do Livramento; Sapiranga; Lajeado; Santo Ângelo; Alegrete; Santa Rosa e Venâncio Aires (https://cidades.ibge.gov.br), de acordo com a tabela que segue:

Tabela 01 - Os 30 maiores municípios sul-rio-grandenses em termos populacionais e seus respectivos PMEs:

\begin{tabular}{|l|l|l|l|l|l|}
\hline Município & Lei $\boldsymbol{n}^{\boldsymbol{o}}$ & Município & Lei $\boldsymbol{n}^{\boldsymbol{o}}$ & Município & Lei $^{\text {o }}$ \\
\hline Alegrete & $5.530 / 15$ & Alvorada & $2.829 / 15$ & Bagé & $5.534 / 15$ \\
\hline $\begin{array}{l}\text { Bento } \\
\text { Gonçalves }\end{array}$ & $5.948 / 15$ & Cachoeira do Sul & $4.404 / 15$ & Cachoeirinha & $4.040 / 15$ \\
\hline Canoas & $5.933 / 15$ & Caxias do Sul & $7.947 / 15$ & Erechim & $5.883 / 15$ \\
\hline Esteio & $6.158 / 15$ & Gravataí & $3.685 / 15$ & Guaíba & $3.292 / 15$ \\
\hline Ijuí & $6.122 / 15$ & Lajeado & $9.844 / 15$ & $\begin{array}{l}\text { Novo } \\
\text { Hamburgo }\end{array}$ & $2.823 / 15$ \\
\hline Passo Fundo & $5.146 / 15$ & Pelotas & $6.245 / 15$ & Porto Alegre & $11.858 / 15$ \\
\hline Rio Grande & $7.911 / 15$ & $\begin{array}{l}\text { Santa Cruz do } \\
\text { Sul }\end{array}$ & $7.315 / 15$ & Santa Maria & $6.001 / 15$ \\
\hline Santa Rosa & $5.219 / 15$ & $\begin{array}{l}\text { Santana do } \\
\text { Livramento }\end{array}$ & $6.910 / 15$ & Santo Ângelo & $3.976 / 15$ \\
\hline São Leopoldo & $8.291 / 15$ & Sapiranga & $5.636 / 15$ & $\begin{array}{l}\text { Sapucaia do } \\
\text { Sul }\end{array}$ & $3.645 / 15$ \\
\hline Uruguaiana & $4.620 / 16$ & Venâncio Aires & $5.701 / 15$ & Viamão & $4.365 / 15$ \\
\hline
\end{tabular}

Fonte: organização da autora, com base no site: http://pne.mec.gov.br/planos-de-educacao/situacaodos-planos-de-educacao / Link: http://simec.mec.gov.br/sase/sase_mapas.php?uf=RS\&tipoinfo=1

Já, no que concerne à revisão temática, foi selecionado um conjunto de textos acadêmicos que abordam modelos de racionalidade que podem, eventualmente, pautar eventos de formação docente - tanto inicial quanto continuada -, a partir das seguintes questões de pesquisa: os registros de artigos, metas e estratégias de formação docente no 
âmbito de alguns dos Planos Municipais de Educação sul-rio-grandenses alinham-se, preferencialmente, ao modelo da racionalidade técnica, ou ao modelo da racionalidade prática ou racionalidade crítica? Com base na problematização dessa escolha de alinhamento, quais as pautas que podem ser incorporadas ao debate mais amplo acerca da epistemologia da formação docente?

Conduzidos por tais questões, os textos foram examinados a partir do procedimento da análise de conteúdo, compreendida como “[...] um conjunto de técnicas de análise das comunicações, que utiliza procedimentos sistemáticos e objetivos de descrição do conteúdo das mensagens" (BARDIN, 2007, p. 38), utilizando-se a técnica da análise temática, onde o “[...] tema é a unidade de significação que se liberta naturalmente de um texto analisado, segundo critérios relativos à teoria que serve de guia à leitura" (BARDIN, 2007, p.105).

As unidades temáticas foram organizadas a partir de duas divisões prévias: a) perspectivas e posicionamentos que indexem o texto examinado a racionalidade técnica e, b) perspectivas e posicionamentos que indexem o texto estudado à racionalidade prática ou também denominada de racionalidade crítica. Tal divisão, a priori, considerou que os registros legais indicariam, de forma mais ou menos clara, a vinculação das estratégias descritas nos PMEs a uma dessas duas racionalidades.

\section{Sobre os modelos de racionalidade...}

A dimensão fulcral do texto (e da pesquisa que dá origem ao mesmo) reside na importância estratégica da formação docente para o planejamento educacional, pois...

Se não houver constante qualificação docente, o professor pode perder o entusiasmo pela profissão. Acredita-se que sem a realização de estudos sistemáticos com vista ao desenvolvimento profissional, o professor não consegue estabelecer e manter a capacidade de analisar as mudanças educativas, além de ter dificuldade de adaptar-se às novas exigências da educação contemporânea (NUNES; OLIVEIRA, 2017, p. 68).

Nesta perspectiva, discutir elementos de formação docente inicial e continuada, em Planos de Educação, pressupõe assumir, deliberadamente, tal importância estratégica, colocando-a como elemento a ser amplamente referendado e debatido nos movimentos e ações de políticas educacionais.

O texto tomou como parâmetro de análise dois modelos de racionalidade: o modelo da racionalidade técnica e o modelo da racionalidade prática ou racionalidade crítica, partindo da 
premissa que, ao manifestar movimentos/ações de formação docente (inicial e/ou continuada), os PMEs filiam-se - de maneira deliberada ou não -, a um ou outro modelo de racionalidade. Desta feita, partimos da compreensão que os registros legais advindos dos Planos de Educação, direcionam práticas e ações para a educação no território municipal, indicando possíveis modelos de racionalidade presentes em artigos (no caso do corpo das leis) e em metas e estratégias (no caso dos anexos da lei).

Quando apresentamos os modelos de racionalidade intencionalmente escolhidos como parâmetro de análise da presente pesquisa, diferenciamos o modelo da racionalidade técnica e o modelo da racionalidade prática ou racionalidade crítica a partir de algumas premissas ou critérios de compreensão teórica.

Assim, no modelo da racionalidade técnica, o docente é visto como um técnico, um mero especialista que utiliza, na sua prática cotidiana, as regras, pressupostos e metodologias que derivam do conhecimento científico e do conhecimento pedagógico (PEREIRA, 1999). O professor é, pois, o responsável por aplicar, com mais ou menos eficiência, os códigos e procedimentos já pré-estabelecidos em relação ao seu campo de saber e atuação. O professor é um especialista em relação a um conhecimento fragmentado, onde o que importa é o desempenho - com algum grau de competência -, das tarefas inerentes àquela função específica.

Em tal modelo de racionalidade, encerra-se a primazia da prática, prioritária diante das 'teorizações', pois a teoria seria considerada uma 'perda de tempo', sendo mais urgente aprender novas técnicas, procedimentos e formas de aplicação, do que novos parâmetros de reflexão. Nesta perspectiva, a prática cotidiana dos professores é alimentada por um certo senso comum basista, imediatista e fragmentário, que maximiza questões cotidianas e pontuais, desprezando reflexões teóricas.

Este modelo epistemológico é mais conhecido entre professores por valer-se do receituário ou livro de receitas, no qual técnicas e procedimentos, já testados e aprovados em realidades diferentes, são repassados ao docente como arquétipos mecânicos e fechados a serem imitados/reproduzidos.

Já, no modelo da racionalidade prática, o professor é considerado um profissional autônomo, que reflete, toma decisões, cria e recria durante sua ação pedagógica (PEREIRA, 1999), ação entendida como um fenômeno complexo, singular, inesgotável, instável e carregado de incertezas e conflitos de valores. Neste modelo, a formação docente é permeada por um princípio de reflexão sobre a prática. 
De acordo com este modelo de racionalidade, a prática não é apenas o espaço da aplicação de um conhecimento científico e pedagógico, mas o lugar apropriado para a criação e reflexão, espaço de caminhos e descaminhos, em que novos conhecimentos são constantemente gerados e modificados (PEREIRA, 1999).

Para este modelo de racionalidade, importam práticas de formação docente que...

... tomem como referência às dimensões coletivas, contribuam para a emancipação profissional e para a consolidação de uma profissão que é autônoma na produção dos seus saberes e dos seus valores [...] a formação contínua deve ser concebida como uma das componentes da mudança, em conexão estreita com outros sectores e áreas de intervenção, e não como uma espécie de condição prévia da mudança. A formação não se faz antes da mudança, faz-se durante, produz-se nesse esforço de inovação e de procura aqui e agora dos melhores percursos para a transformação da escola. É esta perspectiva ecológica de mudança interativa dos profissionais e dos contextos que dá um novo sentido às práticas de formação contínua centradas nas escolas (NÓVOA, 2002, p. 59-60).

Um dos autores que discorre sobre as peculiaridades e propriedades diferenciadas de tais modelos de racionalidade no (s) processo (s) de formação docente é Perez Gomes, quando destaca duas concepções (1995): o professor como técnico especialista e o professor como prático autônomo.

Para Perez Gomes (1995), a ideia do professor como técnico que limita-se a aplicar instrumentos mais ou menos eficientes de ensino, é originária do modelo de racionalidade técnica e, neste sentido, a atividade profissional é instrumental, mecânica, ensimesmada e repetitiva, sendo que o bom professor será aquele que aplicar de maneira mais competente, as técnicas que lhe foram ensinadas.

Segundo o modelo da racionalidade técnica, a actividade do profissional é, sobretudo, instrumental, dirigida para a solução de problemas mediante a aplicação rigorosa de teorias e técnicas científicas. Para serem eficazes, os profissionais da área das ciências sociais devem enfrentar os problemas concretos que encontram na prática, aplicando princípios gerais e conhecimentos científicos derivados da investigação (PEREZ GOMES, 1995. p. 96).

No paradigma da racionalidade técnica, há uma separação entre produção do conhecimento e aplicação prática deste conhecimento, sendo que a aplicação (técnica, instrumental...) é condicionada e derivada (por consequência, dependente) da produção do conhecimento. Neste modelo epistemológico, é possível perceber "a concepção do ensino como intervenção tecnológica, a investigação baseada no paradigma processo-produto, a concepção do professor como técnico e a formação de professores por competências" (PEREZ GOMES, 1995, p. 98). 
Há, portanto, uma separação entre quem produz o conhecimento (teoria) e quem aplica o conhecimento (técnico/professor), não restando autonomia e nem autoria a este último...

... a ideia básica do modelo de racionalidade técnica é que a prática profissional consiste na solução instrumental de problemas mediante a aplicação de um conhecimento teórico e técnico, previamente disponível, que procede da pesquisa científica. É instrumental porque supõe a aplicação de técnicas e procedimentos que se justificam por sua capacidade para conseguir os efeitos ou resultados desejados. (...) $\mathrm{O}$ aspecto fundamental da prática profissional é definido, por conseguinte, pela disponibilidade de uma ciência aplicada que permita o desenvolvimento de procedimentos técnicos para a análise e diagnóstico dos problemas e para o tratamento e solução. A prática suporia a aplicação inteligente desse conhecimento, aos problemas enfrentados por um profissional, com o objetivo de encontrar uma solução satisfatória (CONTRERAS, 2002, p.90-91).

Já, o modelo de racionalidade prática requer um conhecimento na ação, uma reflexão na ação, um protagonismo docente ante ao próprio processo de formação. Tal modelo instaura o "movimento da prática reflexiva" (ZEICHNER, 1993), contrapondo-se à mera transmissão de conhecimentos e/ou técnicas.

Isso porque a realidade apresenta problemas e desafios complexos para os quais não há uma receita pronta "a priori” em qualquer manual técnico ou receituário. Assim, sendo o professor um ser humano e partindo-se do princípio que "a reflexão é atributo dos seres humanos" (PIMENTA, 2002, p. 18), a este cabe tomar as rédeas do seu próprio processo de formação, construindo conhecimentos de forma autônoma, conhecimentos que não se subtraiam diante da simples repetição de receitas, típicas da racionalidade técnica.

... [n]a racionalidade prática [...] parte-se da análise das práticas dos professores quando enfrentam problemas complexos da vida escolar, para a compreensão do modo como utilizam o conhecimento científico, como resolvem situações incertas e desconhecidas, como elaboram e modificam rotinas, como experimentam hipóteses de trabalho, como utilizam técnicas e instrumentos conhecidos e como recriam estratégias e inventam procedimentos e recursos... (PEREZ GOMES, 1995. p. 102).

O professor e as reflexões sobre a prática cotidiana desencadeiam e alimentam o processo de formação, sendo que a separação entre a teoria e a prática, típica do modelo de racionalidade técnica, respondem a uma demanda imediatista, mas não a um processo de formação reflexivo e autoral.

\section{Racionalidades presentes nos PMEs: dos achados da pesquisa}


Se a forma como concebemos o "conhecimento influencia diretamente as ações docentes, como organizar o currículo, escolher os materiais didáticos, planejar as atividades, avaliar os resultados" (MACHADO, 2011, p.7), a maneira como concebemos a formação docente inicial e continuada influencia discursos, articulações, práticas políticas e pedagógicas e, em última instância, planejamentos e projetos educacionais desenvolvidos em razão desta concepção. De tal modo, os registros das concepções, compreensões e previsões legais sobre a formação docente admite antever a racionalidade que atravessa - implícita ou explicitamente -, os Planos Municipais de Educação.

Entretanto, uma lei não se produz desindexada dos sujeitos que a escrevem, orientam e registram. Assim, parece adequado questionar qual a origem autoral dessas compreensões e como elas reverberam no planejamento educacional, mormente, nos textos legais dos Planos de Educação? Como tentativa de resposta, é mister indicar que os planos municipais de educação foram elaborados ou referendados pelos legislativos locais e sancionados de igual maneira pelos executivos locais.

A Lei 13.004/2014 indicava, no art. $8^{\circ}, \S 20$, que "os processos de elaboração e adequação dos planos de educação dos Estados, do Distrito Federal e dos Municípios [... ] serão realizados com ampla participação de representantes da comunidade educacional e da sociedade civil" (BRASIL, 2014). Figura, portanto, no âmbito da legislação, a participação social como elemento fundante para os Planos de Educação.

Todavia, o banco de dados escolhido (http://pne.mec.gov.br/planos-de-

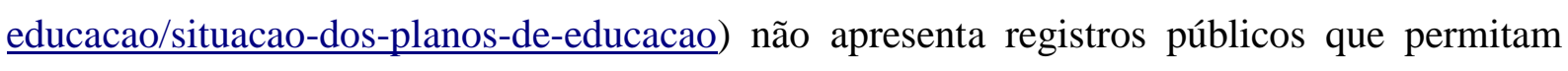
afirmar, com segurança, que as legislações examinadas são frutos de um efetivo debate ampliado, com participação de representantes da comunidade educacional e da sociedade civil, tampouco que os PMEs sejam o resultado de consensos possíveis, pois não há registros completos sobre o processo de elaboração dos Planos. Também, não é possível indicar a autoria dos registros legais (à despeito de qualquer debate sobre representatividade política), pois nem todas as legislações apresentam nomes, cargos, setores ou indicações que autorizem saber quem redigiu a lei que ora interpretamos.

Apesar desta lacuna, há informações que auxiliam a problematizar a autoria dos PMEs. Os trinta planos examinados não são iguais em sua forma, embora na maioria deles apresente o padrão lei (artigos e disposições legais) /anexos (metas e estratégias). Assim, dentre estes itens, nos pareceu particularmente relevante examinar se os planos tinham uma autoria atribuível (e não apenas presumível), no escopo do já citado artigo $8^{\circ}, \S 2^{\circ}$, da Lei 
13.005/2014. Assim, buscamos Fóruns de educação instituídos (em referência ao Art. $6^{\circ}$. Da Lei 13.005/2014); comissões de elaboração; comitês de revisão ou equipes técnicas referenciadas no documento. Tal informação figura em 16 planos municipais, onde são apresentadas as comissões representativas ou técnicas que, efetivamente, redigiram o plano. Conveniente observar que, em todas as comissões, há, ao menos, nominalmente, a presença de representantes de órgãos e entidades classistas de professores (seguramente grandes interessados no assunto 'formação docente').

Outra informação importante, está relacionada à presença (ou ausência) de diagnósticos que justificam/amparam a proposição de metas e estratégias. Tal item está presente em 18 planos municipais de educação e, supostamente, teria o condão de fornecer ao legislador um quadro conjuntural próximo à realidade educacional do território municipal. A presença de diagnósticos como peça de referência para a feitura da lei, em alguma medida, justificaria a escolha de ações de formação docente e, por conseguinte, embasaria, voluntariamente, a opção por uma ou outra racionalidade para o desenvolvimento das propostas, haja vista que o diagnóstico seria um potente indicador do contexto no qual serão desenvolvidos os planos. O registro concomitante de comissões de elaboração e diagnósticos figura em 14 planos. Por fim, 12 planos não apresentam nenhuma descrição que autorize a visualização de comissões ou equipes técnicas de elaboração do texto legal. Tampouco, apresentam diagnósticos acerca da realidade do território municipal.

Mesmo diante das restrições impostas pelo corpus documental escolhido, que nos permite examinar apenas o registro final tornado público na forma de lei - episodicamente acompanhado por detalhamentos como equipe de apoio/redação e diagnóstico circunstanciado - é possível, no entanto, identificar e problematizar as concepções de racionalidade que foram informadas no texto.

Assim, no exame das 30 legislações - corpo da lei e seu anexo -, foi possível visualizar três compreensões que dizem respeito às racionalidades implicadas nos registros dos PMEs: 1) a dualidade dos registros, identificados a uma 'confusão' (deliberada ou não) epistemológica; 2) a ausência de perspectivas materiais para as metas e estratégias que referenciam a formação docente inicial/continuada, e 3) o quanto uma estratégia parece factível no corpo do Plano Municipal de Educação.

A primeira compreensão diz respeito a algo um tanto paradoxal em um primeiro olhar: a dualidade dos registros, identificados a uma 'confusão' (deliberada ou não) epistemológica. Tal dualidade é materializada na manutenção de estratégias que referendam 
práticas de racionalidade técnica ao lado de estratégias que primam pela racionalidade crítica, em todos os PMEs examinados. Desta feita, nos parece factível afirmar que os legisladores, ao elaborar e aprovar os planos, não estavam pautados de forma deliberada em um modelo de racionalidade específico.

Há, portanto, certa 'confusão' epistemológica, que permitiu o estabelecimento de estratégias em ambos os modelos de racionalidade. Essa 'confusão' pode indicar: a) os embates realizados entre legisladores na discussão conceitual dos planos; b) o possível desconhecimento dos mesmos sobre a natureza epistemológica do registro efetuado, bem como suas consequências no campo da prática e, c) a própria natureza heterogênea do conceito e da prática de formação docente, pois...

[...] não existe um modelo de formação de professores a priori, mas modelos que se diferenciam, dadas as concepções de educação e de sociedade [e por isso] as demandas de formação de professores respondem a configurações que se originam nas mudanças ocorridas no mundo do trabalho e nas relações sociais, e as configurações oriundas das diferentes posições que são assumidas em relação aos projetos apresentados pelo grupo que ocupa o poder a partir de determinada correlação de forças (KUENZER, 1999, p. 166).

Todavia, o conteúdo das estratégias permite a percepção de uma disputa - proposital ou não - entre os dois modelos, informando que se o legislador não defende práticas atreladas a racionalidade crítica, também compreende que há movimentos e ações de formação docente inicial/continuada que são iminentemente de racionalidade crítica.

É o caso de municípios que preveem, por exemplo, cursos de aperfeiçoamento em determinadas áreas, compulsório a um conjunto de professores para que os mesmos desenvolvam determinada habilidade (racionalidade técnica), mas que na estratégia subsequente, prevê o investimento das redes públicas em cursos de stricto senso para professores (racionalidade crítica).

A segunda compreensão informa outra situação também aparentemente paradoxal: a ausência de perspectivas materiais para as metas e estratégias que referenciam a formação docente inicial/continuada. A totalidade dos PMEs examinados apresenta uma considerável quantidade de estratégias que discorrem sobre a formação docente, tanto inicial quanto continuada, evidenciando o quanto o tema parece pertinente para o contexto dos planos. Todavia, o conjunto das estratégias é bastante repetitivo e genérico, raramente deixando claro sob quais condições materiais ocorrerá essa formação. 
A quantidade de estratégias sobre a formação docente - tanto inicial, quanto continuada -, muitas vezes de teor próximo ou repetido, nos leva a crer que o legislador compreende formação como a quantidade de cursos ofertados aos seus professores, indicando, de antemão, um princípio epistemológico que afasta o professor do protagonismo requerido. Isto porque...

...a formação não se constrói por acumulação (de cursos, de conhecimentos ou de técnicas), mas sim através de um trabalho de reflexividade crítica sobre as práticas e de (re) construção permanente de uma identidade pessoal. Por isso é tão importante investir a pessoa e dar um estatuto ao saber da experiência (NÓVOA, 1993, p. 25).

A profusão de estratégias que se repetem, exaustivamente, pode indicar uma preocupação retórica que, talvez, não será levada à cabo, justamente pela exaustão de possíveis ações previstas por estas estratégias. Há, assim, uma certa desconcentração de práticas e ações, pulverizando e dispersando o foco de qualquer planejamento mais objetivo.

Uma terceira compreensão incide justamente sobre o quanto uma estratégia parece factível no corpo do Plano Municipal de Educação. Quais as reais possibilidades de que a estratégia planejada, prevista, saia do campo das ideias e figure como materialidade?

Nesta direção, temos a presença de mais um paradoxo - deliberado ou não - que compromete a execução do plano no que diz respeito à racionalidade crítica. Quando as estratégias são genéricas, retóricas, de longo prazo (quase inatingíveis) por envolverem altas quantias de investimento ou a mobilização de inúmeros agentes políticos, elas contemplam uma perspectiva de racionalidade critica. Todavia, quando o texto legal indica estratégias mais factíveis, de fácil e rápida execução, que envolvem ações políticas concretas e pontuais, alastrar-se o modelo da racionalidade técnica.

Assim, a compreensão possível advinda do exame do corpus documental, incide sobre o detalhamento do registro: a grande maioria das estratégias direcionadas para efeitos práticos e imediatos, além de expressarem uma palpável racionalidade técnica, também são exequíveis; enquanto as estratégias claramente vinculadas à racionalidade crítica são abstratas e fluídas (ou de difícil fixação em práticas viáveis). Aparentemente, o legislador compromete-se discursivamente com a racionalidade prática ou crítica mas, concretamente, compromete-se com a racionalidade técnica.

De outro modo, há um grande número de estratégias que são apresentadas a partir da presciência de cursos de atualização docente - inclusive com a previsão de 'colaborações' ou 'parcerias' -, em um movimento que sustenta na perspectiva da ausência, pois... 
Muitos programas de formação contínua têm-se revelado inúteis, servindo apenas para complicar um quotidiano docente já de si fortemente exigente. É necessário recusar o consumismo de cursos, seminários e acções que caracteriza o actual "mercado da formação" sempre alimentado por um sentimento de "desactualização" dos professores (NÓVOA, 2011, p. 23).

Por fim, fica a pergunta: com base na problematização dessa escolha de alinhamento, quais as pautas que podem ser incorporadas ao debate mais amplo acerca da epistemologia da formação docente? Parece que a questão a ser incorporada diz respeito ao protagonismo docente em relação ao próprio processo formativo. Se o legislador foi, aparentemente, paradoxal na proposição do texto legal, o professor pode cerrar fileiras em torno de uma concepção que responda aos seus interesses formativos... afinal, há diversas (e repetidas) possibilidades nos PMEs...

De outra maneira, a compreensão do legislador sobre as necessidades formativas docentes foi, aparentemente, bastante restrita. Há, portanto, o espaço de esclarecimento e diálogo social, acadêmico e de classe em relação ao tema, sobretudo porque os Planos Municipais de Educação, à exemplo do Plano Nacional de Educação, preveem espaços de acompanhamento e monitoramento (Art. $7^{\circ}$. 3 o, BRASIL, 2014).

\section{Conclusão:}

Ao elaborarem seus planos municipais de educação, os municípios atenderam a determinação do artigo 8º da Lei 13.005/2014 - Plano Nacional de Educação. À despeito das determinações contidas neste mesmo artigo, que endereçava aos planos estaduais, distrital e municipais a diretiva de serem elaborados ou adequados "em consonância com as diretrizes, metas e estratégias previstas neste PNE” (BRASIL, 2014), houve espaço para o atendimento de demandas locais e regionais no texto dos planos de educação (até porque não deveriam, forçosamente, organizarem-se como uma cópia do PNE). Dentro dessa possibilidade de autonomia e inovação, cada legislador indexou ao planejamento educacional local (travestido de Plano de Educação) sua compreensão mais alargada sobre a educação, mormente temas como escolarização, ação pedagógica, carreira docente e, entre outros temas o que, particularmente, nos interessa: formação docente.

A partir dessa perspectiva, é possível compreender que os planos locais de educação são portadores do registro de uma determinada compreensão epistemológica no que diz respeito à formação docente. Uma compreensão indexada histórica e ideologicamente, mas 
uma compreensão que indica possíveis ações políticas no campo da formação docente em redes e sistemas de ensino.

Se, por um lado, os Planos Municipais de Educação sul-rio-grandenses examinados mostraram tendências que se apoiam em ambas as racionalidades, por outro lado, ao registrar essa plasticidade de compreensão epistemológica, os planos indicam, com mais intensidade, a seguinte ambiguidade: as estratégias factíveis, passiveis de execução rápida ou que são de ordem prática são vinculadas, claramente, à racionalidade técnica; enquanto as estratégias de longo prazo - com o condão de alterações substanciais e estruturais na formação docente -, que dependerão de legislações regulamentadoras vindouras, são vinculadas à racionalidade crítica.

Isto indica, de forma evidente, que as estratégias imediatas são vinculadas à racionalidade técnica, enquanto as estratégias mediatas ou com prazo indefinido são da seara da racionalidade crítica. Assim, a disputa entre as duas concepções epistemológicas não se dá no campo do registro propriamente dito - visto que os PMEs examinados compreendem registros de ambas as fontes, mas no campo da possibilidade de efetivação real de uma estratégia. O discurso contempla a racionalidade crítica, mas a prática sugere, fortemente, a presença da racionalidade técnica.

\section{REFERÊNCIAS}

BRASIL. Lei 13.005. Aprova o Plano Nacional de Educação - PNE e dá outras providências. Brasília: Casa Civil, 2014. Disponível em: <http://www.planalto.gov.br/ccivil_03/_Ato20112014/2014/Lei/L13005.htm> . Acesso em: 10 abr. 2018.

ALARCÃO, Isabel. Formação continuada como instrumento de profissionalização docente. In: VEIGA, Ilma Passos Alencastro (Org.). Caminhos da profissionalização do magistério. Campinas: Papirus, 1998. pp. 99-122.

CONTRERAS, J. A autonomia do professor. São Paulo: Cortez, 2002.

CURY, C. R. J. Potencialidades e Limitações da Certificação de Professores. Meta: Avaliação. Rio de Janeiro, v. 1, n. 3, p. 297-315, set./dez. 2009.

CUNHA, M. Formação continuada. In. Enciclopédia de Pedagogia Universitária. Marília Costa Morosini [et. all.]. Porto Alegre: FAPERGS/RIES, 2003, p.368.

GARCIA. Carlos Marcelo. Formação de professores: para uma mudança educativa. Porto: Porto Editora, 2005. 
GÓMEZ, Angel Pérez. O pensamento prático do professor - a formação do professor como profissional reflexivo. In: NÓVOA, A. (Coord.). Os professores e a sua formação. Lisboa: Dom Quixote, 1992.

IMBERNÓN, F. Formação docente e profissional: formar-se para a mudança e a incerteza. São Paulo: Cortez, 2001.

KUENZER, Acacia Zeneida. As políticas de formação: A constituição da identidade do professor sobrante. Educação e Sociedade, ano XX, n. 68, p. 163-183, dez. 1999.

MACHADO, N.J. Epistemologia e didática: as concepções de conhecimento e inteligência e a prática docente. 7.ed. São Paulo: Cortez, 2011.

NÓVOA. A. Os professores e a sua formação. Lisboa, Dom Quixote: 1993, p.25.

MAUES, Olgaíses Cabral. Reformas internacionais da educação e formação de professores. Cadernos de Pesquisa, São Paulo, n.118, p.89-118, mar. 2003.

NÓVOA, Antonio. Os professores e sua formação. Lisboa: Don Quixote, 1995.

NÓVOA, Antonio. O passado e o presente dos professores. In: NÓVOA, A. (Coord.). Profissão professor. Porto: Editora Porto, $1995 \mathrm{~b}$.

. Relação escola-sociedade: novas respostas para um velho problema. In: SERBINO, Raquel Volpato e outros (Orgs.). Formação de Professores. São Paulo: Editora da UNESP. 1998.

Formação de professores e trabalho pedagógico. Lisboa: Educa, 2002.

O Regresso dos Professores. Pinhais: Melo, 2011.

NUNES, Claudio Pinto; OLIVEIRA, Dalila Andrade. Trabalho, carreira, desenvolvimento docente e mudança na prática educativa. Educação e Pesquisa. São Paulo, v. 43, n. 1, p. 6680, mar. 2017.

PEREIRA, Júlio E. D. As licenciaturas e as novas políticas educacionais para a formação docente. Educação e Sociedade, ano XX, n. 68, 1999. pp.109-125.

PÉREZ GÓMES, A. O pensamento prático do professor: a formação do professor como profissional reflexivo. In: NÓVOA, A. (org.). Os Professores e sua Formação. Lisboa: Publicações Dom Quixote, 1995. pp. 95-114.

PIMENTA, S. G. Formação de professores: identidade e saberes da docência In. (Org.). Saberes Pedagógicos e atividade docente. 3 ed. São Paulo: Cortez, 2002. p. 15-34. ZEICHNER, K. M. A formação reflexiva de professores: ideias e práticas. Lisboa: Educa, 1993. 